\title{
ADAPTIVE CAR FOLLOWING MODEL
}

\author{
MIKA Péter ${ }^{1}$ \\ ${ }^{I}$ Multidisciplinary Graduate School of Engineering Sciences, Department of Mechatronics and Machine Design, \\ Egyetem tér 1., 9026 Györ, Hungary, e-mail: mika.peter@sze.hu
}

\begin{abstract}
The vehicle dynamics was a very lot developed in the last twenty years. There is a huge gap in the different vehicle models in this field. Researchers need accurate the car following models because of it. There are several mathematical model, which describe the dynamics and the motion of individual vehicles. This models based on a desired velocity, which is kept by the following vehicle and even small gaps will not induce braking reactions. So this behaviour is not realistic.
\end{abstract}

KEYWORDS: adaptive systems, car-following model, microscopic traffic simulation

\section{Introduction}

The efficient transportation system is important in the city. Researchers are therefore seeking solutions to the questions of how the capacity of the road network could be used more efficiently. The key of solution is the steady traffic flow, what is achieve with vehicle built-in and roadside equipment. Both of fields are develops but there are problems in traffic controlling system. Namely the traffic control strategy ordinary optimize the whole network or part of it, ignore the unique vehicle movement. So they optimize the system in macroscopic level.

The unique vehicle movement is taken account in the different car-following model, such intelligent driver model (IDM) [10]. These models gives a new insights for the better description of human drivers [2], [3], [8], [13], [5]. The vehicle manufacturers develops driver assistance system, which is already available for basic driving tasks such as accelerating and braking by means of adaptive cruise control system (ACC) [1], but this is closely guarded secret. Despite of this the researchers must take account this factor in the microsimulation process [6], [7].

Modern cars was equipped some systems (ABS, TCS, ESP, ...), which help the driver the safe transport [9], [11]. These cars provide more safety feeling for the drivers, whose keeps ever smaller distance each other's, besides high speed. It happens quite often that the drivers brakes more than it should have been, because of the less distance. This manoeuvre leads to traffic waves, which decrease the road traffic capacity.

However exist adaptive cruise control ACC, which allows the driver to set a desired speed and following distance and maintains the desired following distance from the leading vehicle, but is less useful in the city. On the one hand, this system is available on premium vehicles (BMW, Audi, Mercedes) and some mid-size vehicles, but there are few this premium vehicles in the Hungarian roads and the route of the roads is not sufficiently proper for this system. For this reason, I suppose that they does not use the ACC so often. On the other hand, the intelligent driver model, which is the basis for the development of an ACC system, 
implements an intelligent braking strategy but a congested traffic if drivers have different conceptions of safe distance, this may lead to strong braking manoeuvres of the IDM, which would not be acceptable in a real-world.

Therefore I developed a new car following model, the adaptive car following model (ACFM), which can change the following vehicle acceleration in attention an safety following distance, which take attention for the road conditions. In this model, the following vehicle wants to keep an safety distance which depends on velocity, coefficient of friction and the slope. Tyre pressure affects the coefficient of friction, therefore it is worthwhile to look into its effect in the future [12]. Furthermore worthwhile to modelling vehicle speed in case of road accident as well [4]. In this paper, I show an enhanced model which based on following distance.

Given the fact that the ACC-equipped vehicles behaviour is different from those that are non-equipped with driver helping system. I must take attention of the human reaction time, which is different at the two case. Despite of it, I do not take attention on to the impact of ACC-equipped vehicles of the traffic flow in this paper, so I chose the reaction time for one second, which is a typical value.

By means of simulation, I investigate the influence of adaptive acceleration and deceleration on the traffic flow characteristics, which based on the following distance. I suppose that all cars has the same behaviour the car-following from point of view. For simulating the modern cars, I propose a new car-following model that also serves as the basis of an implementation in real cars. The model has five behavioural parameters, one of them depends of human behaviour and available all of the vehicles: acceleration and deceleration, desired speed, reaction time, safety standing distance. Growing number of modern vehicles, the ACFM car-following model is needed, which can be easily implemented in the microscopic traffic simulators.

\section{The adaptive car-following model}

In this section, I develop the model equations of the ACFM. To do this I will first present the relevant aspects of the IDM [10]. The IDM implements an intelligent breaking strategy with smooth transitions between acceleration and deceleration behaviour. While in most situations it works well but the actual following distance is less than desired following distance, therefore the following vehicle breaks suddenly and the situation will be considered as critical because of the too strong deceleration.

Therefore I develop a new continuous microscopic single-lane model, which define a sensitiveness factor which influence the acceleration and deceleration, furthermore this factor could be adjustable. Figure 1. depicted the adaptive car-following model architecture and parameters. 


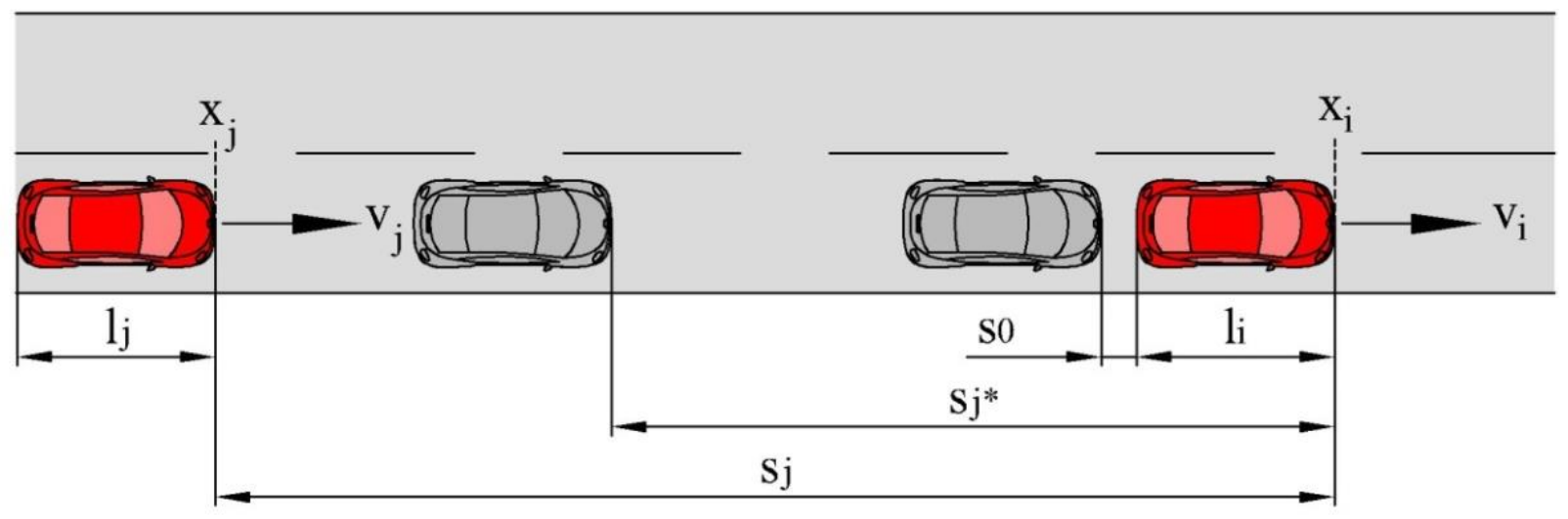

Fig. 1 The adaptive car following model architecture. The figure shows the desired distance $s_{j}^{*}$ what the following vehicle wants to keep. (own editing)

The ACFM drivers assume that the leading vehicle will not stop during a moment, therefore no must keep emergency distance, so the following vehicle get to closer. Even if the leading vehicle will suddenly initiate full-stop emergency brakes without any reason, therefore the following vehicle must keep a distance which enough to stop without crash. This distance is the desired gap $s_{j}^{*}$ which is given by

$$
s_{j}^{*}(t)=l+s_{0}+\tau v_{j}(t)+\frac{v_{j}^{2}(t)}{2 g\left(\mu \pm \frac{e}{100}\right)}-\frac{v_{i}^{2}(t)}{2 g\left(\mu \pm \frac{e}{100}\right)}
$$

Where $l$ is the vehicle length, $s_{0}$ is the safety distance in standing position, $\tau v_{j}(t)$ describe the distance under the reaction time and the last part describe the distance under the maximum break taking into account the coefficient of friction $\mu$, the slope $e$ and the gravity $g$. The $v_{j}$ is the following vehicle velocity and the $v_{i}$ is the leading vehicle velocity.

The following driver wants to move with a road conditions suitable velocity $v_{0}$, more, but no more, so it is necessary to limit the max velocity of the following vehicle.

$$
v_{j}(t)= \begin{cases}v_{j}(t), & v_{j}(t)<v_{0} \\ v_{0}, & \text { otherwise },\end{cases}
$$

The ACFM acceleration is a continuous function in different driving situations. Besides the actual velocity $v_{j}(t)$ the ACFM takes into attention the difference $\left(\Delta s=s-s^{*}\right)$ between the following distance and the desired following distance, which is a sensitiveness factor and given by

$$
\delta(t)=\frac{\sqrt{\Delta s^{2}}}{100}= \begin{cases}1, & \delta>1 \\ \delta, & \text { otherwise }\end{cases}
$$

The breaking term of the ACFM, even in the worst case, where the driver of the leading vehicle suddenly brakes with the maximum possible deceleration, is that the following vehicle may crash with the leading vehicle. In fact, the human drivers rely on the fact that the leading vehicle will not suddenly brakes, therefore come to closer each other, but keeps the desired gap $s_{j}^{*}$.

However, there are situations where the gap is smaller than the desired gap, where the worse-case leads to over-reaction, the ACFM regulate between 0 to max deceleration $b$ with the sensitiveness. 


$$
a_{\text {ACFM }}(t+1)=\left\{\begin{aligned}
\delta a, & \gamma>1 \\
-\delta b, & \text { otherwise, }
\end{aligned}\right.
$$

Where the $\delta$ is the sensitiveness factor and this calculate with the (3) equation. The (4) equation is need that we can decide whether the car accelerate or decelerate in the actual moment.

$$
\gamma(t)=\delta(t)+\beta(t)
$$

If the following car gap is less than the desired gap, than $\beta(t)$ is zero so $\gamma(t)$ will be less than 1 , therefore it must decelerate, otherwise accelerate.

$$
\beta(t)= \begin{cases}0, & s_{j}^{*}(t)>s_{j}(t) \\ 1, & \text { otherwise }\end{cases}
$$

Table 1. Model parameters of the ACFM (typical value)

\begin{tabular}{lc}
\hline \hline Model parameter & typical value \\
\hline Vehicle long $l$ & $5 \mathrm{~m}$ \\
Safety standing distance $s_{0}$ & $0.5 \mathrm{~m}$ \\
Desired speed $v_{0}$ & $120 \mathrm{~km} / \mathrm{h}$ \\
Coefficient of friction $\mu$ & 0.5 \\
Reaction time $\tau$ & $1 \mathrm{~s}$ \\
Maximum acceleration $a$ & $4 \mathrm{~m} / \mathrm{s}^{2}$ \\
Maximum deceleration $b$ & $8 \mathrm{~m} / \mathrm{s}^{2}$ \\
\hline \hline
\end{tabular}

The free $(\max )$ acceleration is characterized by the difference between the gap $s_{j}$ and desired gap $s_{j}^{*}$. The desired gap $s_{j}^{*}$ is composed of the vehicle length $l$, safety standing distance $s_{0}$, the velocity-dependent distance $\tau v_{j}$ and a dynamic contribution, which is only active in non-stacionary traffic corresponding to situations in which $\Delta v \neq 0$. This last contribution mean an 'intelligent' driving behaviour because it define the sensitiveness factor, which lead to a smooth transition on deceleration.

\section{Results of the simulated ACFM}

The ACFM based on the following assumptions.

- The acceleration of the vehicle is not constant in time.

- The vehicles does not changing lanes.

- The vehicles has not got ACC system.

- The actual acceleration and deceleration is always lower than the maximum value.

- There is a desired gap at any moment what the following vehicle wants to keep.

I executed an examination which simulate two different traffic situations as Kesting [1] did. Figure 2. displays simulations of a mildly critical cut-in situation. The first vehicle suddenly brakes because a vehicle come to front of him. The following vehicle driving at the same velocity, $80 \mathrm{~km} \mathrm{~h}^{-1}$ and her following gap $s_{j}(0)=10 \mathrm{~m}$ and the model parameters 
shown in table 1. It is seen that the desired gap is approximately $30 \mathrm{~m}$ and this not decrease because of the $\Delta v=0$ at the beginning. The situation is not really critical because of the following gap is not less than $10 \mathrm{~m}$. Consequently, the ACFM model does not result uncomfortable deceleration $\left(2 \mathrm{~m} / \mathrm{s}^{2}\right)$ and crash. In contrast the IDM model [1], deceleration reaching the maximum possible value $\left(8 \mathrm{~m} / \mathrm{s}^{2}\right)$, but still the following car regain her velocity a same time.

Notable, when the gap has minimum or maximum than both vehicles moving at the same velocity for a moment, $80 \mathrm{~km} / \mathrm{h}$. After the incident in the ACFM model, the vehicle speed decrease under the desired speed. After that it increase and exceed the desired speed then decrease. So the ACFM driver behaviour is significantly different than the other models.
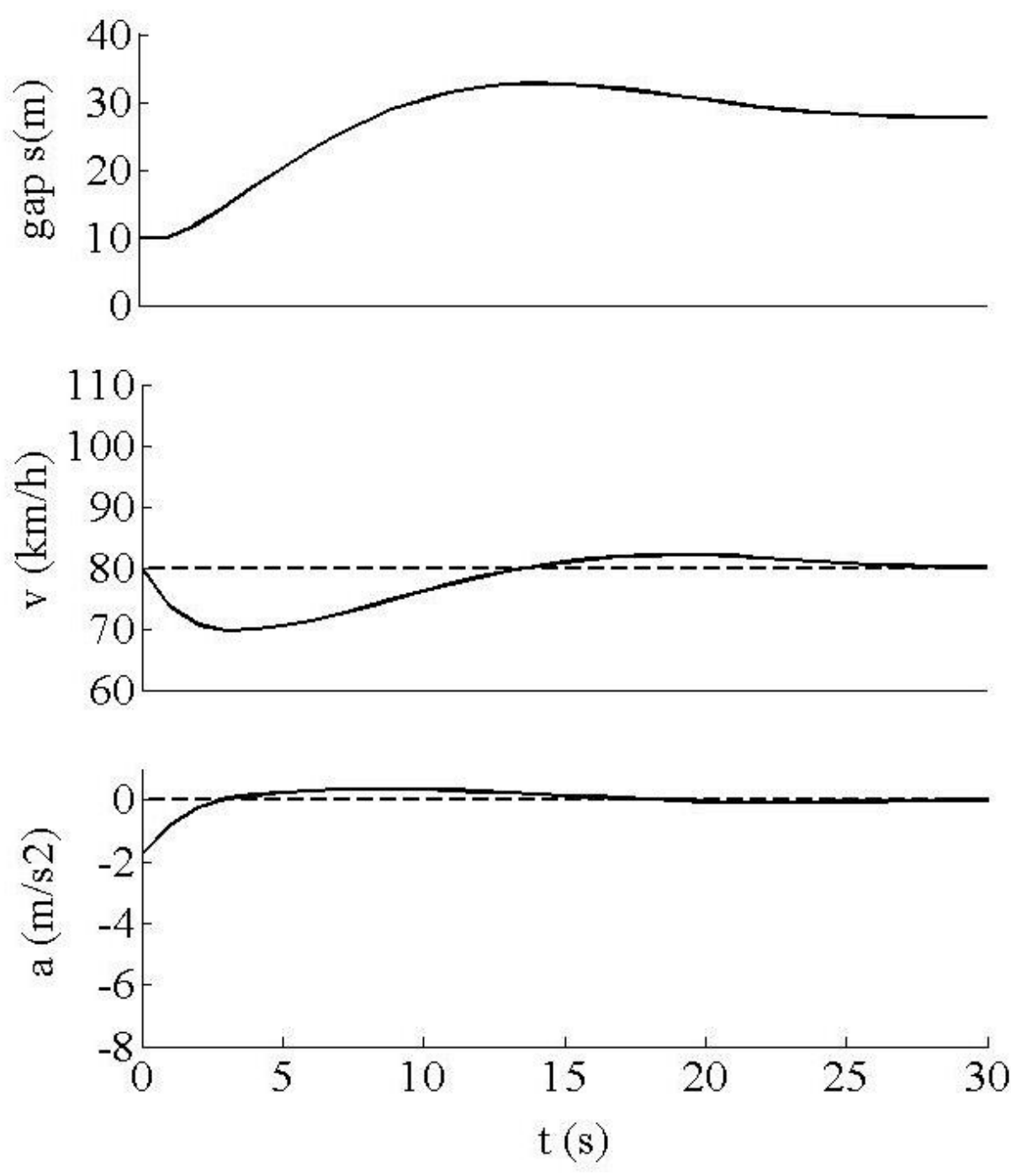

Figure 2. Response of an ACFM vehicle (solid line the following vehicle, dashed line the first vehicle), when suddenly another vehicle get in front of the following vehicle. The initial velocities of both vehicles is $80 \mathrm{~km} / \mathrm{h}$, and the initial gap is $10 \mathrm{~m}$. We can considered as a mildly critical situation. (own editing)

Another circumstance, when the following vehicle speed is much higher than the first vehicle. So it result seriously critical situation which is depicted in Figure 3. The initial gap same as the previous situation $s_{j}(0)=10 \mathrm{~m}$, but the following vehicle approaching rapidly and he need emergency braking to avoid a crash. Inspite of emergency brake the gap decrease almost zero, so this situation is very dangerous. Thus it can been seen that the vehicle gets the 
first vehicles velocity as we can see in the previous situation. For this case both the IDM and the ACFM models lead to initial decelerations near the maximum value. However the deceleration of the ACFM vehicle slowly decreases towards the comfortable deceleration with smooth transition. In contrast the IDM vehicle [1], remains in emergency mode for nearly the whole braking manoeuvre. If compare the minimum gap of the IDM and the ACFM then we find that the ACFM leads to a closer gap $(5.5 \mathrm{~m}$ compared with $1.4 \mathrm{~m})$, but the velocity drop both of models are the same about $66 \mathrm{~km} / \mathrm{h}$.

The maximum deceleration is influence the stability of the platoon of vehicles. I suppose that the third vehicle will crash in the queue in this situation. An further investigation light onto this and delineate the stability limits.
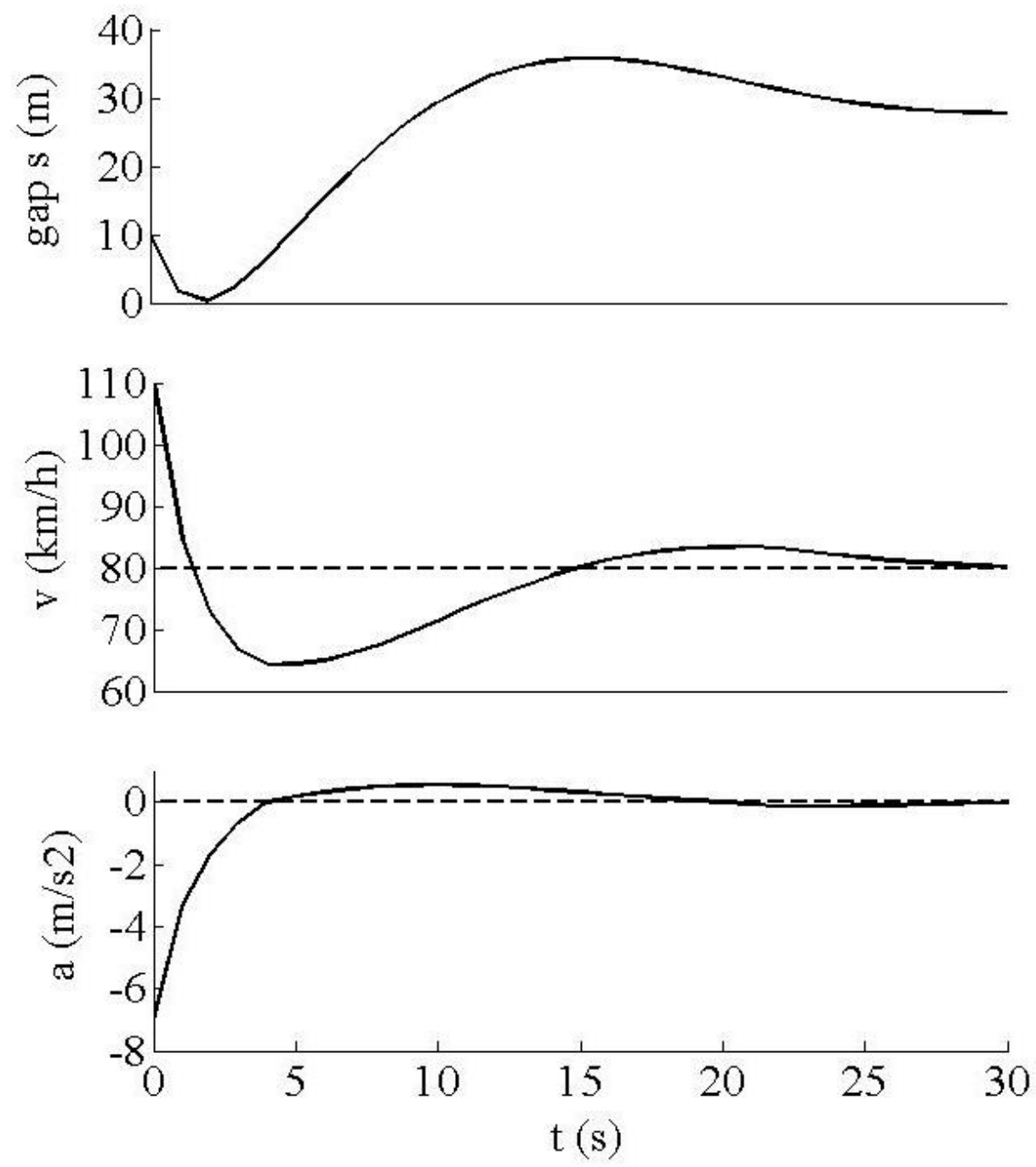

Figure 3. Response of an ACFM vehicle (solid line the following vehicle, dashed line the first vehicle) when suddenly another vehicle get in front of the following vehicle. The initial velocity of the lane-changing vehicle $80 \mathrm{~km} / \mathrm{h}$, while the initial velocity of the following vehicle is $110 \mathrm{~km} / \mathrm{h}$. This is an critical traffic situation. (own editing)

\section{CONCLUSION}

In order to characterize the ACFM model, I investigated the implications of the adaptive acceleration and deceleration. From the examination is stated that the ACFM is triggered a more relaxed reactions, which suspense the wave spread therefore improve the traffic flow. I 
was made a simple model, which describe the traffic flow more realistic, because of the sensitiveness factor. The ACFM drivers specify the difference between the following distance and the desired following distance which influence the intensity of the braking.

The proposed car-following model is simple, has a few parameters with real value and reproduce a realistic traffic dynamics. This model to be used in microsimulation modelling and a built-in vehicle equipment as well. It take attention the road conditions and the human reaction time as well. Therefore the ACFM leads a plausible microscopic behaviour for single-lane model. The acceleration and deceleration is more relaxed than the other models and the velocity relaxation time is more. An interesting open question is the sensitiveness factor, which is specified by the different between the gap and the desired gap. An further investigation may light onto this question.

\section{ACKNOWLEDGMENT}

The presented research is sponsored by the EFOP-3.6.1-16-2016-00017 to create internationalization, educators, researchers and students, developing knowledge and technology transfer as tools of intelligent specialization at István Széchenyi University. This work is connected to the scientific program of the Regulatory algorithm research to reduce congestion.

\section{REFERENCES}

[1] A. Kesting, M. Treiber, D. Helbing. Enhanced intelligent driver model to access the impact of driving strategies on traffic capacity. Phil. Trans. R. Soc. A 2010 (368), 4585 $-4605$.

[2] B. S. Kerner. Physics of traffic: empirical freeway pattern features, engineering applications, and theory, Springer - Verlag, Berlin, Germany 2004.

[3] D. Helbing. Traffic and related self-driven many-practical systems. Rev.Mod. Phys 2001 (73), $1067-1141$.

[4] G. Hoxha, A. Shala, R. Likaj. Vehicle speed determination in case of road accident by software method and comparing of results with the mathematical model, Journal of Mechanical Engineering - Strojnícky časopis 2017 (67), No. 2, 51 - 60. DOI: 10.1515/scjme-2017-0017

[5] I. Luspay, T. Tettamanti, T. Varga. Forgalomirányítás: Közúti jármüforgalom modellezése és irányítása, Budapest, TYPOTEX 2011.

[6] K. É. Gilicze, G. Debreczeni. Közúti forgalmi áramlatok mikroszkopikus és makroszkopikus szemléletmódú jellemzése. Közlekedéstudományi szemle 2010 (60), 16 -20 .

[7] W. Leutzbach. Introduction to the Theory of Traffic Flow, Springer - Verlag, 1988, Berlin, pp. 204.

[8] M. Treiber, A. Kesting, D. Helbing. Delays, inaccuracies and anticipation in microscopic traffic models. Physica A 2006 (360), 71 - 88.

[9] M. Treiber, A. Hennecke, D. Helbing. Congested traffic states in empirical observations and microscopic simulations. Physical review E 2000 (62), 1805 - 1824.

[10] M. Treiber, D. Helbing. Realistische Mikrosimulation von Straßenverkehr mit einem einfachen Modell. 2002, Dresden. 
[11] O. Derbel, T. Peter, B. Mourllion, M. Basset. Generalized velocity-density model based on microscopic traffic simulation. Transport 2015 (33), No. 2, 489 - 501. DOI: $10.3846 / 16484142.2017 .1292950$

[12] P. A. Azodo. Survey Road-Tyre contact patch pattern and wear related aspects. Journal of Mechanical Engineering - Strojnícky časopis 2017 (67), No. 2, 5 - 12. DOI: 10.1515/scjme-2017-0013

[13] S. Ossen, S. P. Hoogendoorn, B. G. Gorte. Inter-driver differences in car-following: a vehicle trajectory based study. Transp. Res. Rec. 2007 (1965), 121 - 129. 